\title{
Evolution of Telugu Language Teaching and Challenges to Present Curricular Trends
}

\author{
Dr. K. Mallareddy \\ Lecturer in Telugu, Government Degree College, Nirmal, Andhra Pradesh, India
}

\begin{abstract}
Mother gives Mother Tongue along with cultural and literary wealth of words, so it must be protected forever. This article intended to describe the significance of Mother Tongue for the development of Education system. Majority of Languages in the world are in danger and disappearing. Language is like a stream may always changes its way, the way should be provided with modern Technology by the society, otherwise there will be no technology without language. I proved in this paper how the Telugu Language is running towards danger to disappear and the way to protect it.
\end{abstract}

\section{Introduction}

"If you talk to a man in a language he understands, that goes to his head. If you talk to him in his language that goes to his heart." - Nelson Mandela.

The Telugu Language is the second largest language in India, $10^{\text {th }}$ largest language among the 15 major spoken languages on the globe. It was divided between 1500-1000 BC from the Proto-Dravidian language which is the Mother Language of south Indian languages. Telugu Language recognised as official language of Andhra Pradesh State of India and spoken by about 200 Million people throughout the world, which is 8 times of the Australian population and more than half of the USA population. Number of national and international Books, Magazines and Journals have been published in Telugu Language from various places of the world. World Telugu Conferences (Prapancha Maha Sabhalu) have been uniting the Telugu people all over the world since lost 37 years and $4^{\text {th }}$ World Telugu Conference will be held in Tirupathi, AP in the month of December , 2012. Written literature in Telugu was started in $11^{\text {th }}$ century AD with Adikavi Nannaiah and widely expanded with many Genres like Purana, Kavya, Shathaka, Dwipada, Natakam(Drama), Navala(novel), Katha(story), Kathanika(short story) etc.

UNESCO published a Atlas of World's Languages in Danger and Disappearing and indicated that if $60 \%$ of students neglect this education in Mother Tongue, the Language will disappear very soon. "It is estimated that, if nothing is done, half of 6000 plus languages spoken today will disappear by the end of this century. With the disappearance of unwritten and undocumented languages, humanity would lose not only a cultural wealth but also important ancestral knowledge embedded, in particular, in indigenous languages."[1] "At present, roughly 5,100 languages are spoken around the globe.... Yet many indicators suggest that within a generation or two, not more than 100 of these languages will survive. Languages are dying out every bit as quickly as species. While in the latter case, plants and animals disappear from the history of nature never to be seen again, with the demise of languages, entire cultures are vanishing from the history of civilization never to be lived again."- Wolfgang Sachs.

Such a biggest language Telugu is listed among the Disappearing Languages, because the peculiar circumstances prevailed among Telugu speaking people those are-

1. The devotees are Telugu people and the Brahmans(Pujaari) also belong to Telugu but the Puja (process of devotion) takes place in Sanskrit.

2. Judges ,Under trailers and Lawyers are belong to Telugu but the arguments in the Court have been conducted in English.

3. Teachers and students are Telugu people but the Medium of Instruction followed in schools and colleges is in English.

The influence of other languages is unavoidable and flourishing the language but at the same time every Language as well as Mother Tongue should be protected.

\section{Evolution of Telugu Language Teaching}

The British Linguist Halden proved that the Telugu Language is suitable for teaching sciences in India. In 1854 Sir Charles Wood proposed an Educational Dispatch and given priority to Mother Tongue Education in India. Mr. J A Yates officer of Vishaka, Godavari Dist. School Examinations was first time studied the process of Telugu Language teaching in 1906 and for the first time he observed the difference between spoken and written forms of Telugu Language in his essay Reminiscences. "I could see no reason for teaching them a language they would never hear from man of the higher castes, literate or illiterate was not possible, I asked, to 
find a cultivated current Telugu, for their instruction? A parallel might be found in England if the children of the slums were taught Elizabethan English or chancerians English or older west saxan, or to make the parallel more exact, a hotch-potch of all these, but of course no parallel of the sort could be found for no one in England had thought of inventing such a conglomeration of archaisms as a means of modern instruction."These differences of written and spoken forms of Telugu led to Grandhika and Vyavaharika Bhashodyamalu. Madrass University appointed a Committee to recognise the Standard Language to be followed for teaching and evaluation In 1910.

"In Telugu the dialect used in ordinary conversation differs so much from that used in grammatically written books. For the same reason a foreigner may be able to read and understand a Telugu book, but at the same time may be unable to converse with the Indians, or understand what they say to him owing to this great difference between the colloquial and the grammatical dialect, in the present work the former has been kept distant from the later".[2]

Gidugu Ramamurthi Pantulu who lead the Vyavaharika Bhashodyamam, united all the Telugu Language Teachers at Vishaka District to seek support to develop Spoken form of Language for teaching and publish in the Text Books. In 1926 Andhra Vishwakalaparishattu established and issued guide lines for the language to be followed for publishing the Text Books as well as process of Teaching. Navya Sahitya Parishat(New literacy Association) was formed In 1936 which was running a periodical called Prathibha was encouraged in creative free verses of literary writings.

A committee was established under the guidance of PSR Apparao to give suggestions for Nationalise the Text Books. A Conference with delegates taken place under the presidency of Pingali Laxmikantham to decide the Language style to be followed in the Telugu Text Books. They decided to divide the Telugu Text Books into 2 Types based on the style of the language followed in the Text Books.

1. $\mathrm{I}^{\text {st }}$ language Text Books - Text Books for the Mother Tongue people in which the Language followed was Sarala Grandhika Bhasha (simple written language).

2. II ${ }^{\text {nd }}$ Language Text Books. Text Books for those who opted Telugu as second language, in which followed Vyavaharika Bhasha (spoken style of language) in the Text Books.

A protest against to the Grandhika Bhashodyamam was became very strong Sri Srinivasa Ayyangar released a pamphlet on Life or Deaths - A Plea for Vernaculars. Tata Subramanya Shastri in his essay on Andhra Bhasha Samskarana paved way for borrowing Anyadeshas (words from other languages) to support Vyavaharika Bhashodyamam. Burra Sheshagiri Rao given valuable speeches on importance of Vyavaharika Bhasha at Madras Rajadhani Kalashala. Telugu a periodical of Gidugu Ramamurthi and Varthmana Vyavaharikandra Basha pravarthaka samajam of Kandukuri Veereshalingam Panthulu supported for Vyavaharika Bhasha Publications. Panchagnula Adi Narayanashastri unanimously resolved to follow the Vyavaharika Bhasha as Bodhana Bhasha (Language of Teaching) in Abhinava Kavi Panditha Sabha(An association of poets). Komarraju Laxmanarao established Telugu Bhasha Samithi and encouraged to start the writings of Ensyslopideas in Telugu Language. Telugu Bhasha Samithi was taken over by Potti Sriramulu Telugu Univetsity(PSTU), Hyderabad.

\section{Modernision of Telugu Language Teaching}

Andhra Pradesh Government instituted a Committee for the development of the Telugu Language under the president ship of Mr. JPL Gwynn on 28.12.1966. The committee submitted its report to the government on 29.3.1967. "Our committee as a whole endorses the view of Dr. Krishnamurthi on the need to adopt a modern standard Telugu style for all text books, and records the prompt action be taken by the government on the Lakshmi kantham committee's report. We consider that the institute of Telugu should be the authority to give guidance in future on the form of modern standard Telugu to be adopted in the text books, We also consider that responsibility for writing nationalised school text-books in Telugu and getting them published by the Andhra Pradesh text Book press may be handed over to the Institute".[3]

On the recommendations of the committee the the AP Government formed an official organisation called Adhikara Bhasha Sangam, Telugu Academy ( a statutory body) was established in 1969 and started Telugu as the Medium of Instructions in Higher Education from 1970. The Telugu Academy has been publishing the Text Books of all subjects in Telugu Language. By the result the modernisation of Telugu Language Teaching and Research Activities have been started with the help of Individuals, Institutions, Agencies and others. All the countries in the world introduced Two Language Formula(Bilingual System) to introduce one more Language besides Mother Tongue at school level education. But in India(Multilingual country) Central Advisory Board of Education was proposed Three Language Formula that is-

1. Mother Tongue

2. English or any Other European Modern Language

3. Hindi in Non-Hindi States and any Indian Modern Language in Hindi speaking states. 
This Three Language Formula led to communal riots and created threats to National Integration in India. Kothari Commission rectified the inequalities in the above formula and proposed a new formula called Modified Three Language Formula. That is-

1. Mother Tongue or Regional Language

2. Indian Official Language or Assisted Language( Hindi or English)

3. Any Indian or Foreign Modern Language ( Any one from Group-1\&2)

This Three Language Formula was introduced in Andhra Pradesh State and prepared the Text Books according to the standards of the students. So many modifications have been taken place in the preparation of Telugu Text Books as well as Telugu Teaching. In Telugu curricular plan Introduced the objectives that to be achieved behavioural changes in the students according to their standards. Language skills like LSRW where introduced in Primary Stage (1-5 classes), besides the Language Skills Comprehension of the language development, Vocabulary, Language expressions have also been introduced. Linguistic analysis of language and Literary Concepts along with cultural aspects introduced at Upper-primary and Higher stages ( 6-10 classes). These curricular plans intended to impart creative thinking and Poetic Expressions in their Mother Tongue. The separate curriculum was framed for the students those who were opted for Telugu as second language. The topics for them were introduced intended to create interest among the students in Telugu Language and Telugu Literature.

\section{Challenges to Present Curricular Trends in Telugu Language Teaching}

In the modern and technical society the Telugu Students are not showing a minimum interest to study in Mother Tongue (Telugu Language). For their uninterested reason in learning the Telugu Language is that, it is not need based and not showing further opportunities for getting job. It is also not helping to solve their daily problems faced in the modern society, for ex. Even though after completion of 15 years of continuous of study in their Mother Tongue, The students are unable to write an application on their own Language without mistakes. They are unable to fill forms in Bank, Post Office etc. moreover the required scientific and technical vocabulary was not created and there is no coinage of certain words in Telugu like computer, Laptop etc. which was done successfully in Tamil Language. The present Telugu Language Curriculum was not clearly defined the objectives to be achieved and skills to introduced at various levels of Education System. Text Books were not modernised on the present needs of the society. The formal texts and Grammar parts were followed since the language education started. The texts were almost same at Intermediate and Graduation level. The influence of other languages on Telugu Language also created dislike among the Telugu students.

"The mother tongue opens the door, including its own grammar, to all grammars, in which it awakens the potential for universal grammar that lies within all of us. It is the valuable asset people bring to the task of language learning. For this reason, the mother tongue is the master key to foreign languages, the tool which gives us the fastest, surest, most precise, and most complete means of accessing a foreign language. Successful learners capitalize on the vast amount of linguistic skills and world knowledge they have accumulated via the mother tongue. For the beginner, becoming aware of meanings automatically involves connecting them with the mother tongue - until the FL has established an ever-more complex network for itself."'[4]

In Andhra Pradesh State of India majority of colleges in Higher Education are following the Telugu Language as the medium of instructions, But the students are very poor in communicative skills in their Mother Tongue resulted in failure of all other subjects also. So almost all the colleges including Universities running in Telugu Medium showing very low percentage of result(below 40\%), some of the institutions shown $0 \%$ of results. The failure of students in Higher Education system are not taken care of by the Government Administration, Universities and Colleges and still neglect in imparting skills in Mother Tongue. By the result the students are not in a position to write a simple application in their own Mother Tongue. The students also not showing interest to attend the Telugu classes regularly lead to failure in the Mother Tongue. As a student, continues study of fifteen years in Mother Tongue as medium of instruction finally led to fail (fail means getting les then 35 marks out of 100) is a miserable condition which must be rectified by the government as well as Universities.

Some agencies like Telugu Samrakshana Samithi, CP Brown Academy, Saraswathi Vidhya Peetam, Telugu Rakshana Vedhika working for the development of Telugu Language. Saraswathi Vidhya Peetam has been running schools in Telugu Medium with high standards up to secondary level(10 $10^{\text {th }}$ standard $), C P$ Brown Academy, Hyderabad publishing Sahithi Sravanthi a periodical encouraging the Telugu Writers by Publishing research Articles in Telugu Language. It has been giving awards every year on the name of Telugu Bharathi Puraskaram ( 2.5 lakh cash prize and Gold Medal) to the eminent personalities who dedicated their life for the development of Telugu Language. It is also connecting the Telugu People via its website all over the world. The PSTU, Telugu Academy, Telugu Bhasha Sangam were also encouraging in Teaching, Research and Publishing to develop the Telugu Language. But it is not the adequate assistance to develop the Telugu Language and to improve the results among Telugu students. 


\section{Conclusion}

Telugu Language should be modernised according to the needs of the present day society. Need based education and placements should be increased to the Telugu Learning students. Especially education system should introduce the Language skills in curriculum, than they will be able to learn other Languages also. Natural Language processing in Telugu must be done to create new language software, Vocabulary and new fonts. Text Books should be modernised with computer technology and soft skills. Online Conferences, econtent development, Websites, Blogs, Digital Library, Web Magazines must be developed in Telugu Language. Information and Communication Technology (ICT) must be used in the teaching of Telugu Language Teaching and Learning process.

\section{References}

[1] Moseley, Christopher (ed.). Atlas of the World's Languages in Danger, 3rd edn. Paris, UNESCO Publishing. Online version, 2010 http://www.unesco.org/culture/en/endangeredlanguages/atlas

[2] A.S. Arden, A Progressive Grammar of Telugu Language, Society for promoting Christian Knowledge , Madras, India, 1905.

[3] Gwynn Committee Report : Report of the committee setting up on institute for the development of Telugu Language, Andhra Pradesh, Govt G.O.M.S. No.3051, Education, dated 28.12.1966.

[4] Butzkamm, W. We only learn language once: The role of the mother tongue in EFL classrooms, Death of a Dogma, Language Learning Journal, 31. (2003).

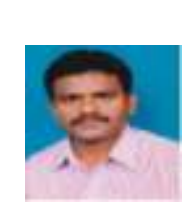

\section{Authors' Biography}

DR. K. MALLAREDDY received M.A(TELUGU) from Osmania University and honoured with Gold Medal in M.A. for securing highest marks in the University Examinations. Received M.Phil \& Ph.D from Osmania University. Received Teacher Training Certificate and Appointed as Teacher in 1996. Appointed as Lecture in Telugu through Andhra Pradesh Public Service Commission (APPSC) in 2002. Now working as Lecturer in the Asst. Professor Cadre. Published No. of articles in Regional Daily News Papers, Attended National \& International Seminars, actively participated in State level and National level Work Shops. 